\title{
Combinação iterativa de modelos de previsão de séries temporais por erro percentual absoluto
}

\section{Daiana Medeiros da Silva Vinícius Guilherme Abrantes Anna Regina Corbo}

\author{
Centro Federal de Educação Tecnológica Celso Suchow da Fonseca \\ CEFET-RJ, 20271-110, Rio de Janeiro, RJ \\ E-mail: daiana.medeirosdasilva@gmail.com
}

\begin{abstract}
RESUMO
De acordo com [4], as técnicas estatísticas para modelar dados de demanda têm requerido a devida atenção tanto de engenheiros quanto de gerentes de produção. E para estes tomarem boas decisões é preciso que possuam uma visão clara do futuro, de modo que a decisão tomada hoje seja a mais apropriada não apenas para o presente momento, mas sim ao momento futuro quando esta decisão tiver efeito [3].

Modelos estatísticos de previsão são ferramentas utilizadas para fornecer subsídios aos gestores para o processo de tomada de decisões. O desenvolvimento de estudos que possibilitem o emprego de uma ferramenta estatística capaz de agregar as potencialidades de mais de um modelo, pode auxiliar para que decisões mais confiáveis sejam tomadas. O estudo de métodos de previsão já é abordado e utilizado como uma ferramenta de apoio à tomada de decisões por diversas organizações há um tempo considerável. Porém, estudos utilizando diferentes métodos de previsão e a combinação destes métodos de maneira a diminuir o erro de previsão ainda não têm sido amplamente explorados, apesar de o primeiro estudo [1] sobre o tema datar de 1969.
\end{abstract}

Segundo [1, 2], a previsão pode se tornar mais acurada quando realizada por uma combinação de modelos de previsão. Desta forma, este trabalho foi inspirado no estudo de [2] que utilizou técnicas de combinação de previsão para análise da volatilidade de ações no mercado de valores como referência. Sendo assim, é proposta uma nova maneira para combinar previsões denominada Combinação por Erro Percentual Absoluto.

Seja uma série temporal, modelos de previsão individual $i$ (onde $i=1, \cdots, n$ ), já conhecidos cuja a previsão para esta série no tempo $t$ é dada por $F_{i}(t)$ e $\varepsilon_{i}$ são seus respectivos valores para o erro percentual absoluto. A combinação destas previsões individuais por meio de pesos ponderados de forma iterativa, é dada pela expressão:

$$
F_{c}(t)=W_{1}(t) F_{1}+W_{2}(t) F_{2}+\cdots+W_{n}(t) F_{n}
$$

Onde:

$F_{c}(t)=$ Previsão combinada no tempo $t$;

$W_{i}(t)=$ peso para a previsão $F_{i}$ do método $i$ no tempo $t$

Tal que $\sum_{i=1}^{n} W_{i}(t)=1$

A ponderação por pesos iterativos tem por objetivo "extrair" o melhor das características que cada método possui individualmente e transferi-las para a previsão combinada no intuito de enriquecê-la, ou seja, incrementar a sua acurácia.

A iteratividade na ponderação dos pesos é composta de quatro etapas, que visam garantir uma maior parcela (ou percentual), na composição da previsão combinada num certo tempo $t$, ao método que tiver obtido o menor erro absoluto no período $t-l$ imediatamente anterior. Para que pudessem ser calculados os pesos ponderados a partir do erro percentual absoluto, a priori, fora realizado o cálculo da representatividade que cada par de métodos individuais possuía em relação 
a cada um dos métodos. Para tal, foi necessário agrupar os erros percentuais absolutos dos métodos dois a dois de modo que fosse gerado um valor de erro equivalente aos dois erros individuais.

Se $\varepsilon_{i}$ é o erro percentual absoluto do método de previsão $i$, o erro equivalente associado $E_{i}^{e q}$ ao método de previsão $i$ é dado por:

$$
E_{i}^{E q}=\frac{\varepsilon_{j} \cdot \varepsilon_{k}}{\varepsilon_{j}+\varepsilon_{k}}
$$

Onde $j, k \neq i \forall i=1, \ldots, n$.

Logo, o peso dado ao modelo de previsão $i$ no tempo $t$ é dado por

$$
W(t)_{i}=1-E_{i}^{e q}(t)
$$

Note que os pesos são sempre atualizados a cada nova previsão; proporcionando uma capacidade de conferir uma maior ponderação ao método que obteve o melhor resultado na previsão mais recente, ratificando o caráter recursivo desta metodologia.

O modelo foi testado com dados de volume físico industrial dos setores de veículos automotores e de bebidas do Estado do Rio de Janeiro, cuja base de dados foi obtida de modo livre junto ao IBGE. Além disso, utilizou-se os modelos de previsão individual de Média Móvel, Combinação Aritmética, Suavização Exponencial Simples e Suavização de Holt-Winters.

Como resultado, destaca-se a melhor assertividade do novo modelo quando comparado ao método de média móvel, de suavização simples e até mesmo de combinação por média aritmética em relação ao setor de bebidas. Porém, nos índices relativos à indústria de veículos automotores, esta nova técnica apresentou melhores resultados apenas quando comparada aos da média móvel e de suavização simples. Contudo, o modelo proposto não superou o método de Holt-Winters, o qual obteve a melhor capacidade de predição em comparação com todos os modelos abordados.

Palavras-chave: Combinação de Previsões, Modelos Estatísticos de Previsão e Combinação por Erro Percentual Absoluto.

\section{Referências}

[1] BATES, J., \& GRANGER, C. The Combination of Forecasts. Operations Research Quarterly, 20, p. 451-468. 1969.

[2] CAVALERI, R.; Combinação de Previsões Aplicada à Volatilidade. Dissertação de M. Sc., Universidade Federal do Rio Grande do Sul Faculdade de Ciências Econômicas Programa de PósGraduação em Economia, Porto Alegre, RS, Brasil, 2008.

[3] CORRÊA, H. L.; CORRÊA, C. A.; Administração de produção e operações: manufatura e serviços: uma abordagem estratégica, 2 ed. São Paulo, Atlas, 2008.

[4] PELLEGRINI, F. R.; Produção metodologia para implementação de sistemas de Previsão de Demanda, Dissertação de M.Sc., Universidade Federal do Rio Grande do Sul Escola de Engenharia Programa de Pós-Graduação em Engenharia de Produção, Porto Alegre, RS, Brasil, 2000 . 